\title{
Evaluation of climate change impact on Blue Nile Basin Cascade Reservoir operation - case study of proposed reservoirs in the Main Blue Nile River Basin, Ethiopia
}

\author{
DEMELASH WONDIMAGEGNEHU \& KASSA TADELE \\ Arba Minch University, PO Box 21, Ethiopia \\ demewon21@gmail.com; kassatad@yahoo.com
}

This study mainly deals with evaluation of climate change impact on operation of the Blue Nile Basin Cascade Reservoir. To evaluate the impact of climate change, climate change scenarios of evapotranspiration and precipitation were developed for three periods. Output of ECHAM5 with RCM for the A1B emissions scenario were used to develop the future climate change scenarios. A hydrological model, HEC-HMS, was used to simulate current and future inflow volume to the reservoirs. The projected future climate shows an increasing trend in both maximum and minimum temperature and in evapotranspiration, but precipitation shows a fluctuating trend in the next century. Relative to the current condition, the average annual open water evaporation for the Beko-Abo and Mandaya reservoirs show increasing trend whereas the Border Reservoir shows a decreasing trend. Comparison of the base period and the future period average annual inflow volume shows an increase for Beko-Abo and Mandaya, but at Border Reservoir a decrease in volume is observed. The average annual power generation projected using HEC-ReSim also shows an increase at the Beko-Abo and Mandaya hydropower station, whereas a slight decrease occurs for Border hydropower station.

On average, the time based and volumetric reliability of the reservoirs was estimated to be more than $90 \%$. The resilience of the reservoirs is below $50 \%$ and their vulnerability is less than $50 \%$. Therefore, these performance indices reveal good performance of the reservoirs except regarding the speed of recovery of the reservoirs from failure because the reservoirs will not able to recover rapidly from failure to a safe state. 